\title{
DRIVING SIMULATOR EVALUATION OF A VEHICLE REAR-MOUNTED HEAVY BRAKING LIGHT WITH AND WITHOUT DISTRACTION
}

\author{
Michael Regan, ${ }^{1}$ Thomas Triggs, Eve Mitsopoulos-Rubens, \\ Mark Symmons, Nebojsa Tomasevic \\ Monash University Accident Research Centre (MUARC) \\ Melbourne, Victoria, Australia \\ ${ }^{1}$ French National Institute for Transport and Safety Research (INRETS) \\ Lyon, France \\ E-mail: michael.regan@muarc.monash.edu.au
}

\begin{abstract}
Summary: Rear-end collisions comprise a large proportion of all vehicle crashes. A variant of the standard centre high mounted stop light (CHMSL) that flashes under conditions of heavy braking was developed to reduce the incidence and severity of rear-end collisions. The developer of the Heavy Braking Light commissioned MUARC to conduct a driving simulator evaluation of the effectiveness of the Heavy Braking Light. Forty-two participants completed a series of simulator drives that were designed to examine whether participants' braking performance under certain conditions was more effective in response to a heavily braking vehicle fitted with the Heavy Braking Light compared with a heavily braking vehicle fitted with a standard CHMSL. Among other things, it was found that, relative to the CHMSL condition, participants reacted by braking in a shorter time at an intermediate headway to the Heavy Braking Light, and braked harder in response to the Heavy Braking Light at both a near and intermediate headway. The results suggest that the Heavy Braking Light is a device that, through widespread use, may contribute to a reduction in the incidence and severity of rear-end collisions.
\end{abstract}

\section{INTRODUCTION}

Rear-end crashes represent about one-quarter of all vehicle crashes (e.g. Horowitz, 1994). Such incidents may occur for any number of reasons, including following too closely for the conditions, and inattention. There are several human factors approaches that can be taken to decrease the risk of a rear-end crash. Of relevance in the current context are approaches designed to encourage following drivers to respond more effectively (e.g., in less time) to a braking lead vehicle in a way that is commensurate with braking severity.

Several systems have been developed to alert following drivers that the driver of the lead vehicle may brake, and include devices that activate only when the accelerator is released quickly. For example, the Advance Brake Warning System (ABWS) relies on a quick release of the accelerator pedal to illuminate the brake light for one second only (Shinar, 1995). If the driver of the lead vehicle brakes immediately after releasing the accelerator, as he/she might in emergency braking, the brake light appears to observers to have been lit continously. Simulator testing of such systems has been promising (e.g., Shinar, Rotenberg \& Cohen, 1997). However, field evaluations of the ABWS have demonstrated only a marginal benefit (Shinar, 1995). 
A number of deceleration indicator systems, some of which utilise a flashing light, have also been developed and tested. These devices do not provide advance warning of a braking episode but convey information to the following driver of the braking vehicle's deceleration rate (e.g., Olson, Aoki \& Battle, 1989; Koter, 1994). While such systems are now available on some production vehicles, these systems have met with varying degrees of success (see Regan, Triggs, Mitsopoulos, Symmons \& Tomasevic, 2001, for a review).

In summary, a range of devices has been developed to provide advance warning of a braking episode to a following driver. Devices have also been developed that provide information regarding the rate of deceleration of the braking vehicle. At the time of undertaking the current study, however, no other investigations known to the authors had reported on, and evaluated, a device that operated in the same way as the Heavy Braking Light described in this paper. The purpose of the current study, therefore, was to evaluate the effectiveness of this Heavy Braking Light using a driving simulator. The Heavy Braking Light comprises an array of flashing LEDs integrated into the standard CHMSL. It flashes at a rate of $4 \mathrm{~Hz}$ under conditions of high deceleration - defined as $0.5 \mathrm{~g}$ or more. It operates as a standard CHMSL when deceerlation rates fall below $0.5 \mathrm{~g}$. It was expected that the increased alerting properties of the flashing light would lead to more efficient braking by the following driver under circumstances which might otherwise lead to a greater likelihood of a rear-end collision. The circumstances of interest in the current study were short time headways and distraction.

\section{METHOD}

\section{Participants}

Forty-two participants (31 males and 11 females) took part in the study. All participants were aged between 24 and 42 years $(M=30.9$ years). All held a current, full, car driver's licence, drove regularly, and had been licenced for between 2 and 24 years $(\mathrm{M}=12.0$ years).

\section{Apparatus}

The MUARC driving simulator was used in the study. At the time of data collection, it consisted of a Ford Falcon sedan mounted on a motion platform. Simulations were projected onto four screens: three forward and one rear facing, and a range of traffic sounds were delivered through a quadraphonic sound system. For additional detail, refer to Regan et al. (2001).

\section{Procedure and Simulator Drives}

Each participant completed a single session, during which he/she performed seven simulator drives: a Familiarisation drive; a Practice drive; a Brake Light Demonstration drive; and four Test drives. Each drive was carried out on a straight section of two-lane residential road, which had a speed limit of $60 \mathrm{~km} / \mathrm{h}$ (about $37 \mathrm{mph}$ ). The purpose of the Familiarisation drive was to familiarise participants with the virtual visual environment and with the control dynamics of the simulator vehicle. The Practice drive gave participants the opportunity to practice travelling at, and maintaining, time headways behind other vehicles of 1.0 and 1.4 seconds. The Brake Light Demonstration drive provided participants with experience in following and responding to a car 
fitted with the Heavy Braking Light. This drive was preceded by a brief description of the device - specifically, that it flashes in the event of heavy braking by the lead vehicle.

Each Test Drive comprised 14 "following episodes." Each episode commenced when a vehicle moved from the side of the road into the path of the simulator vehicle. The lead vehicle then travelled ahead of the simulator vehicle while maintaining a time headway of 1.0 or 1.4 seconds. After several seconds the lead vehicle either braked or did not brake, and then moved out of the path of the simulator vehicle, allowing the simulator vehicle to continue on to the next episode. The 14 following episodes were characterised as follows: four heavy-braking episodes (deceleration rate of $0.5 \mathrm{~g}$ ); four gentle-braking episodes (deceleration rate of $0.08 \mathrm{~g}$ ); two twophase braking episodes (gentle followed by heavy braking); and four no-braking episodes.

An additional component to the Test drives was a distraction task. While driving, participants were asked to look for billboards positioned on the sides of the road. Each billboard had three letters printed on it. Participants' task was to indicate, by pressing the appropriate button on the steering wheel (right or left, at the 10 and 2 o'clock positions, respectively), whether the letters formed a word or a non-word (right button - word; left button - non-word). Half of each following episode type was coupled with presentation of a billboard (distraction). The remaining following episodes involved no billboards (no distraction). The positioning of the billboards was such that participants would be required to read and respond to a billboard at the same time as any deceleration by the lead vehicle. A tree was positioned several metres in front of each billboard so that the billboards could not be seen from a distance. There were also additional trees lining both sides of the road to minimise the chances of participants predicting which trees might have billboards behind them. In general, participants' task was to observe the speed limit, not to overtake, and to respond to any braking by the lead vehicle as appropriate. Nevertheless, participants were advised that the billboard task was their primary task.

Test drives 1 and 2 were identical except for the presence of the standard CHMSL in drive 1, the presence of the Heavy Braking Light in drive 2, and different billboard stimuli in drive 1 to those in drive 2. Similarly, Test drives 3 and 4 were identical to each other, with the exception that drive 3 involved the standard CHMSL, and drive 4 incorporated the Heavy Braking Light along with different billboard stimuli to those in drive 3 . The sequence of following episodes within drives 1 and 2 was randomly selected with the sequence the same across the two drives. Similarly, the order of following episodes within drives 3 and 4 was randomly selected with the same order used across both drives. Presentation of the four Test drives was counterbalanced both within and across drive pairs.

\section{RESULTS}

\section{Experimental Design and Analysis}

There were three independent variables, with all being repeated measures. They were: brake light design (CHMSL and Heavy Braking Light), presence of distraction (distraction and no distraction), and headway (near and intermediate). A near headway was defined as a time headway of 1.0 second, and an intermediate headway as a time headway of 1.4 seconds. 
Two questions were of interest here. Firstly, under conditions of heavy braking and no distraction, is braking performance more effective in response to the Heavy Braking Light relative to the CHMSL at both a near and an intermediate headway? Secondly, under conditions of heavy braking and at a near headway, is braking performance more effective in response to the Heavy Braking Light compared with the CHMSL in the presence of distraction relative to its absence? Using the data from the heavy braking episodes and the no distraction condition only, a brake light design by headway repeated measures analysis of variance (ANOVA) was carried out to address the first question. Using the data from the heavy braking episodes and the near headway condition only, a brake light design by distraction repeated measures ANOVA was undertaken to examine the second question.

Braking performance was assessed with five dependent variables: reaction time to brake, maximum brake pressure, time to reach maximum brake pressure, minimum headway distance, and reduction in time headway. Each dependent variable was analysed separately. Prior to analysis, the data were screened for outliers and normality. Data which departed significantly from normality were treated with a square root transformation. Only the results from the reaction time to brake and maximum brake pressure variables are presented here.

\section{Reaction Time to Brake}

Reaction time to brake was defined as the elapsed time, in seconds, from the onset of illumination of the lead vehicle's brake light to when the participant in the simulator vehicle first applied pressure to the brake pedal. These data are shown in Figure 1 as a function of brake light design and headway, under conditions of no distraction. The analysis revealed that participants responded in significantly shorter time to the heavily braking lead vehicle at a near headway than at an intermediate headway $(\mathrm{F}(1,62)=23.36, \mathrm{p}=0.00)$. Also, while there was no significant difference in mean brake reaction time between the brake light designs $(F(1,62)=3.23, p=0.08)$, importantly there was a significant interaction between brake light design and headway $(F(1,62)=5.03, p=0.03)$. Figure 1 shows that the mean brake reaction time was shorter for the Heavy Braking Light than for the CHIMSL at an intermediate headway, but not at a near headway. Simple main effects analysis revealed that the interaction was indeed driven by the longer mean brake reaction time at an intermediate headway in the CHMSL condition compared with the Heavy Braking Light condition $(F(1,62)=4.42, p=0.04)$. No difference was found at the near headway.

The second analysis examined the effect of brake light design on brake reaction time at a near headway in the presence and absence of distraction. These data are summarised in Figure 2 . The analysis revealed that the mean time taken to respond to the braking lead vehicle was not significantly influenced by brake light design $(F(1,72)=0.89, \mathrm{p}=0.35)$, and that this pattern applied across distraction conditions $(\mathrm{F}(1,72)=1.52, \mathrm{p}=0.22)$. Nevertheless, there was a significant main effect of distraction overall $(F(1,72)=30.00, p=0.00)$, with a shorter mean brake reaction time found in the absence of distraction than in its presence. 


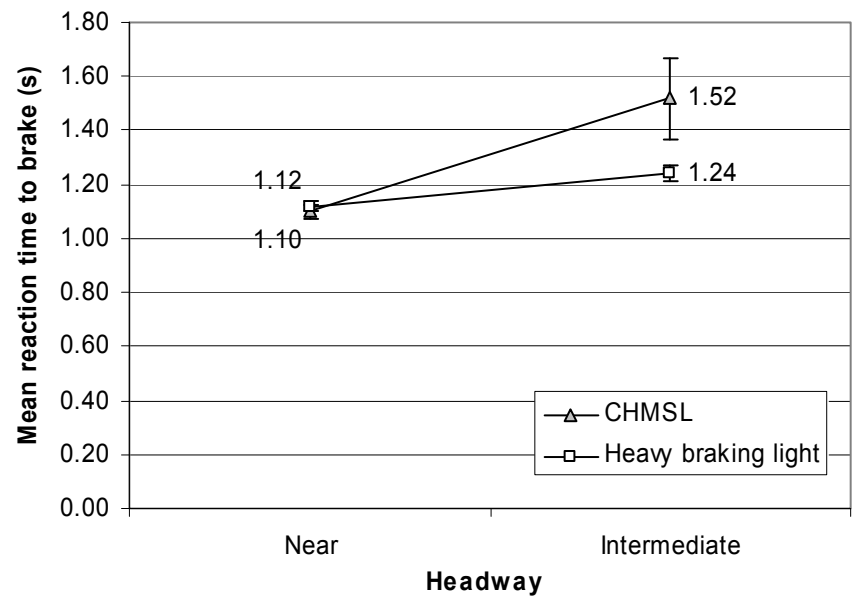

Figure 1. Mean reaction time to brake (seconds) in response to the CHMSL and the Heavy Braking Light at a near and at an intermediate headway under no distraction conditions

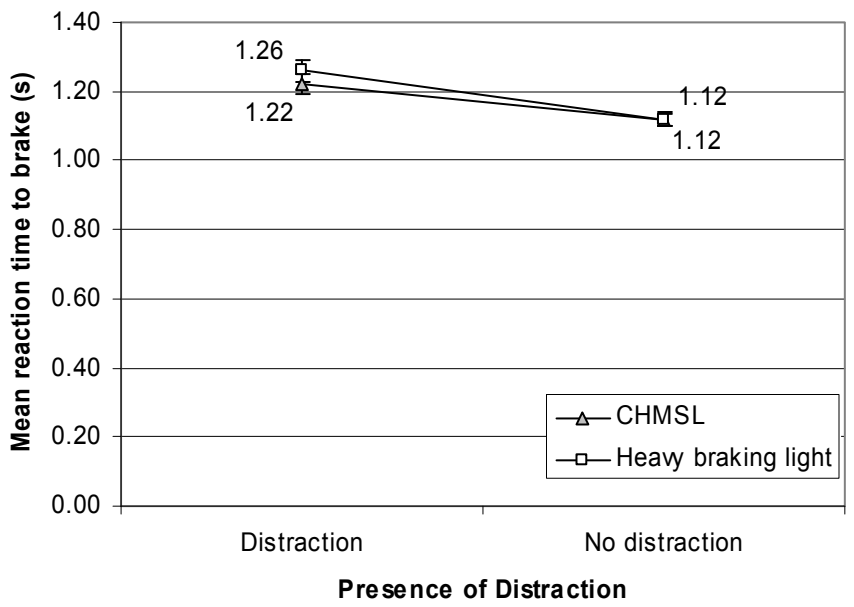

Figure 2. Mean reaction time to brake (seconds) in response to the CHMSL and the Heavy Braking Light under conditions of distraction and no distraction and at a near headway

\section{Maximum Brake Presssure}

Maximum brake pressure was defined as the peak amount of pressure applied to the brake pedal of the simulator vehicle, between the time the lead vehicle's brake light was illuminated and the time it was extinguished. Figure 3 shows that participants braked harder in response to the Heavy Braking Light than to the CHMSL, at both a near and an intermediate headway. The analysis revealed a significant main effect of brake light design $(F(1,63)=13.10, p=0.00)$, confirming that the Heavy Braking Light led to harder braking than the CHMSL. The interaction between brake light design and headway was not significant $(\mathrm{F}(1,63)=0.00, \mathrm{p}=0.98)$. The analysis also showed that, overall, participants applied significantly more pressure to the brakes in response to brake light illumination at a near headway than at an intermediate headway $(F(1,63)=113.99, p=0.00)$.

Figure 4 shows that, at a near headway, participants braked harder in response to the Heavy Braking Light than to the CHMSL in both the presence and absence of distraction. While the 
analysis revealed that the observed overall difference in maximum brake pressure between the brake light design conditions was significant $(F(1,67)=25.96, p=0.00)$, the interaction between brake light design and distraction presence was not $(\mathrm{F}(1,67)=0.81, \mathrm{p}=0.37)$. The main effect of distraction presence was also not significant $(F(1,67)=0.06, p=0.80)$.

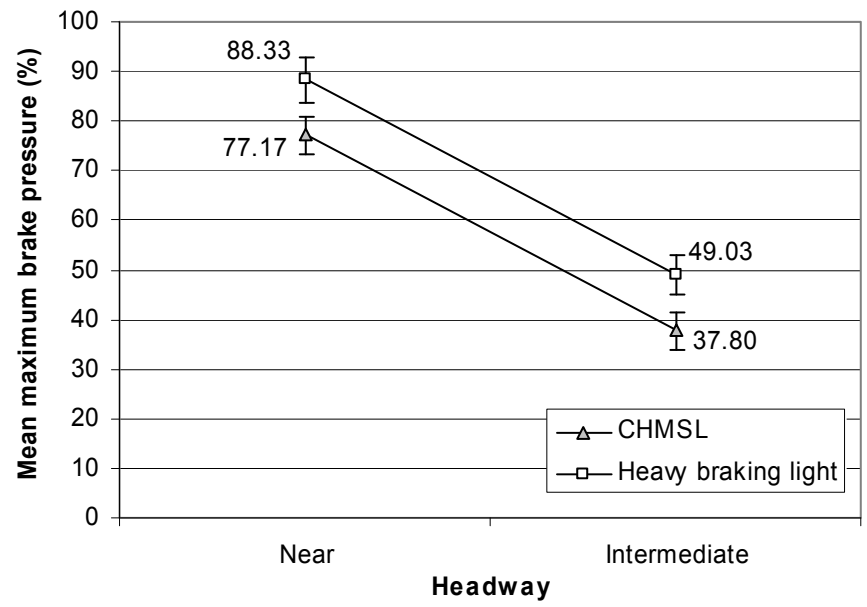

Figure 3. Mean maximum brake pressure (\%) in response to the CHMSL and the Heavy Braking Light at a near and at an intermediate headway under no distraction conditions

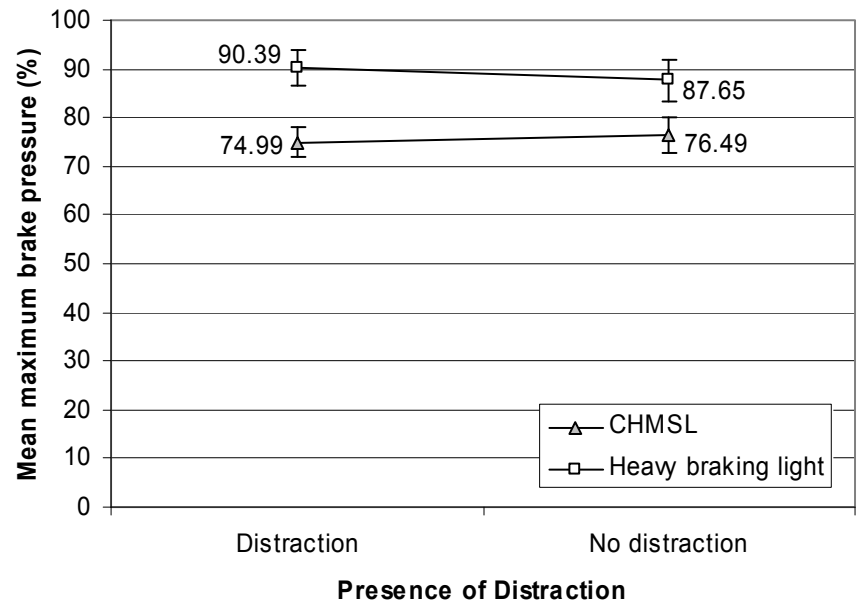

Figure 4. Mean maximum brake pressure (\%) in response to the CHMSL and the Heavy Braking Light under conditions of distraction and no distraction and at a near headway

\section{CONCLUSIONS}

The aim of the study was to evaluate, in a driving simulator, the effectiveness of a variant of the standard CHMSL that flashes under conditions of heavy braking. Participants reacted by braking in a shorter time (280 milliseconds less time) to the Heavy Braking Light than to the CHMSL at an intermediate headway in the absence of distraction. This is likely to have important practical implications. It is estimated that, at $60 \mathrm{~km} / \mathrm{hr}$, a 280 millisecond reduction in brake reaction time for a driver following a vehicle fitted with the Heavy Braking Light would translate into a maximum possible reduction in stopping distance of 4.6 metres. However, a brake reaction time 
advantage for the Heavy Braking Light was not observed at a near headway in the absence of distraction. One explanation for this outcome is that participants might have been more aroused and primed to respond to any brake light, flashing or constant, at such a small time headway. Also, participants' attention may have been more focussed on the rear of the lead vehicle.

Participants braked harder in response to the Heavy Braking Light than to the CHMSL in the situations examined - that is, under conditions of no distraction at an intermediate headway, and at a near headway in both the presence and absence of distraction. However, neither a brake reaction time nor a maximum brake pressure advantage was found for the Heavy Braking Light under conditions of distraction relative to no distraction at a near headway. The absence of a distraction by brake light design effect might be because, at a near headway, participants were heavily focussed on the lead vehicle. Indeed, participants were aware that the lead vehicle might brake at any time. Consequently, participants may have traded off performance on the distraction task in favour of maintaining the driving task. Unfortunately, because of the absence of a distraction condition at an intermediate headway it is not known whether such a trade-off would have also been put into practice at the longer headway. This is a subject for further investigation.

Taken together, the findings of the simulator evaluation of the Heavy Braking Light are largely positive. They suggest that the Heavy Braking Light evaluated here is a device that, through widespread use, may contribute to a reduction in the incidence and severity of rear-end crashes.

\section{ACKNOWLEDGMENTS}

We are grateful to YoungKing Pty Ltd for funding this study through the Australian Department of Transport and Regional Service's Commercialising Emerging Technologies program.

\section{REFERENCES}

Horowitz, A.D. (1994). Human factors issues in advanced rear signalling systems. Proceedings of the Fourteenth International Technical Conference on the Enhanced Safety of Vehicles (Vol. 2). Munich, Germany, 1511-1516.

Koter, R. (1994). Advanced indication of braking. Proceedings of the International Conference on Safety and the Environment in the 21st Century. Tel-Aviv, Israel, 619-637.

Olson, P.L., Aoki, T., \& Battle, D.S. (1989). The use of LED lamps for turn and stop signal presentations (Report No. UMTRI-89-35). Ann Arbor, MI: University of Michigan Transportation Research Institute.

Regan, M., Triggs, T., Mitsopoulos, E., Symmons, M., \& Tomasevic, N. (2001). Simulator evaluation of the YoungKing Heavy Braking Light (Unpublished consultancy report). Melbourne, Australia: Monash University Accident Research Centre.

Shinar, D. (1995). Field evaluation of an advance brake warning system. Human Factors, 37, 746-751.

Shinar, D., Rotenberg, E., \& Cohen, T. (1997). Crash reduction with an advance brake warning system: A digital simulation. Human Factors, 39, 296-302. 